\title{
DUAL-USE RESEARCH AND TECHNOLOGY OF CONCERN: INCREASE OF RISKS IN MODERN LIFE SCIENCE AND GLOBALIZATION OF BIOETHICS
}

Farida NEZHMETDINOVA, Kazan State Agrarian University, Address: 420015, Karl Marx st, 65, Kazan, Russia, Republic of Tatarstan, ayratvaliev@mail.ru (corresponding author)

Sergey YAKHIN, Kazan State Agrarian University, Address: 420015, Karl Marx st, 65, Kazan, Russia, Republic of Tatarstan, jcm61@mail.ru

Nail ADIGAMOV, Kazan State Agrarian University, Address: 420015, Karl Marx st, 65, Kazan, Russia, Republic of Tatarstan, Damir KHALIULLIN, Kazan State Agrarian University, Address: 420015, Karl Marx st, 65, Kazan, Russia, Republic of Tatarstan,

\begin{abstract}
Modern life sciences represent the sphere of natural and exact sciences, which include scientific research of living organisms such as microorganisms, plants, animals and human beings. For example modern biology spreads quickly in such spheres as robotics, computer systems, psychology, linguistics and different social subjects, giving rise to new promising directions and interdisciplinary spheres. At the same time a number of researchers mark that technical-technological possibilities of changing fundamental basics of existence of humans and nature are being created. The article based on the analysis of tendencies of development of the technology and recent discussions about dual- use research and technology of concern, justifies the increasing role of bioethics. Of particular concern is received wide spread production and use of genetically modified organisms (GMOs), carrying a serious risk for human and animal health, biological diversity on the planet. This requires special mechanisms and prevention, such as humanitarian expertise and bioethics. This is due to the fact that the high rate and intensity of development of science and technology have created conditions of uncertainty, lead to increased risks to life and human welfare, the sustainable development of society and nature. It has been suggested that regulation of these risks at the global level, which in turn emphasizes the growing global nature of bioethics.
\end{abstract}

Keywords: dual-use research and technology of concern, modern life science, tendencies of development of science and technology, risks, bioethics.

\section{INTRODUCTION}

The modern stage of development of the world economy is characterized by the transition of countries to a new technological base of economic systems, based on the use of the advanced achievements in biotechnologies, information science and nanotechnologies, including those in agriculture, medicine, veterinary, ecology and other spheres (Global Technology Revolution 2020). This technological mode is formed with the help of converging technologies based on synthesis of technical and biological systems by using nanotechnologies, design of live organisms, new nature use and robotics, new medicine as well as in high humanitarian technologies and development of different kinds of management (Roco and Bainbridge, 2004). The technological factor has become the one defining economic growth in modern world economy (Reports OECD...)

At the same time the vast majority of research and foresight analytical documents, prepared with the participation of experts in different field simultaneously, express serious concern connected both with dual use converging technologies and the possibility of managing present and perceived risks (Johnston, 2011).

Currently and in the near future, technology convergence defines a new strategy of civilization development. This transformation carries with it not only great hopes for the solution of global problems, but also significant risks of loss of humanity the path of sustainable socio-cultural evolution. It becomes clear that creates technological opportunities to change the fundamental basis of human existence and nature. This is due to the risk of preservation of living organisms to their biological nature, biological properties, strategic relationships and characteristics, prevent large-scale loss of biological integrity.

In this case, the situation is "irreversible" and "transience" of living systems generates not only opportunities to solve global problems, but also serious risks of deterioration in the quality of human life and conservation of biodiversity. It is obvious that the NBIC technologies carry with them real risks of negative changes of the fundamentals of living

Copyright (C) 2017 The Authors. Published by Aleksandras Stulginskis University. This is an open-access article distributed under the terms of the Creative Commons Attribution License (CC-BY 4.0), which permits unrestricted use, distribution, and reproduction in any medium, provided the original author and source are credited. 
systems, including humans and nature. The problem requires a scientific solution. The aim of this research is the analysis, evaluation, and selection tools to reduce these risks. The subject of research is the international experience in regulation of the risks of dual-use technologies on the example of bioethics. A research objective is the definition of a practical tool such as bioethics, which enables to perform the function of the humanitarian examination of the modern dual-use technologies.

\section{RESEARCH METHODS}

The main methods used in this study were: foresight, comparative analysis, simulation and prognostics. Many scientists and experts think that at present and in the future converging technologies will define a new strategy of civilization evolution. In the beginning of the 21-st century the term "convergence of technologies" or "converging technologies" became well established in scientific literature, where it comprises a wide range of processes - both convergence of separate spheres of science and technologies per se. For the first time this term was voiced in 2002 in the report on converging NBIC technologies under the editorship of M.K. Roco and W. Bainbridge, where it meant a synergetic combination of N-nano, B-bio, I-info and C-cogno technologies (Roco and Bainbridge, 2004).

The Russian scientists and the present director of the Kurchatov Institute Mikhail Kovalchuk proposed his own version of combining the same four spheres of knowledge. The article "Convergence of science and technologies $-\mathrm{a}$ breakthrough to the future" published in the 1-2 issues of the "Russian nanotechnologies" magazine in gives conceptual basics and serious arguments in favor of the BIO-NANO-INFO-COGNO convergence (NBIC) (Kovalchuk, 2011). It is gratifying that contrary to purely technological solutions of the future development of NBIC technologies, M.V. Kovalchuk includes also humanities in this process. In Russia NBIC technologies have also recognized as priority directions in development of innovative economy. In particular, this has been mentioned in the Concept of long-term social-economic development of the country till 2020, in the Long-term forecast of scientific-technological development of Russian Federation (till 2030), in the list of critical technologies and etc.

NBIC convergence has not only huge scientific and technological meaning. Technological possibilities unfolding during the NBIC convergence will inevitably cause serious cultural, philosophical and social upheavals. In particular this concerns the revision of traditional understanding of such fundamentals notions as life, mind, a human being, nature and existence. It cannot be ruled out that from the certainty based on everyday experience the humanity will have to transfer to understanding of the fact that in the real world there are no clear boundaries between many phenomena which were previously considered as dichotomy: live and inanimate, reasonable and unreasonable, natural and artificial, thinking and programmed, real and virtual (Pride and Medvedev, 2008). This list could be continued but it is a topic for a separate serious inter-disciplinary analysis.

At the same time a number of researchers mark that technical-technological possibilities of changing fundamental basics of existence of humans and nature are being created. It is not by chance that life sciences take centre stage. Today, life sciences represent the sphere of natural and exact sciences, which include scientific research of living organisms such as microorganisms, plants, animals and human beings. On the one hand history of such sciences goes back for thousands of years. While there was the humanity, there also was a necessity in curing diseases, in creating the environment comfortable for living, in food, water and etc. They are used in healthcare, agriculture, medicine, pharmaceutical and food processing branches of science. The book of L. Magner "A history of the life sciences" gives a very complete and interesting description of this (Magner, 2002).

On the other hand, modern biology spreads quickly in such spheres as robotics, computer systems, psychology, linguistics and different social subjects, giving rise to new promising directions and interdisciplinary spheres. Today life sciences are advanced technologies based on the latest achievements of science and technique. By their strategic importance this approaches can quite be compared with the whole complex of nuclear and space technologies. That is probably why they are becoming a core of the new architecture of science based on NBIC convergence. Biotechnologies really have positive large-scale influence on very diverse spheres of human activity. It is new ways of treatment and medicines, food and many other things which raised the level of life and health quality. Unfortunately, there not only positive results but also the consequences which are apocalyptic in their character (Frischknecht, 2014).

It is not by chance that such notions as risk and safety are used in scientific works and other spheres more and more often, and they have given life to such specific phenomenon, which German sociologist Ulrich Beck named with the term "the other modern" of "the society of risk" (Beck, 2000). These changes give rise to "constellations of possibilities" which place a man before a choice of a certain line of development out of many possible ways. And this rightly stresses the change of the meaning and use of the term "risk", which moves from the category of personal space to the global level, at first. Second, if in the previous century the risk was considered as a result of insufficient development of technologies and scientific knowledge, today the risks appears in the situations when the technological and scientific progress are in abundance (Nezhmetdinova, 2010).

This concern is shared not only by scientist and their academic communities but also by large international organizations. Thus in January 2013 the World Economic Forum (WEF) presented another annual report from the "Global Risks" series which coincided with coming meeting of world leaders in Davos in Switzerland (Reports WEF, 2013). The WEF project of Global Risks began at the forum in 2005. Since then the report on global risks has been recognized as one of the leading world publications related to global risks. The annual report defines risks of global importance and proposes business leaders, governments and civil society tools to understand them as well as a method of identifying their interrelations (Reports WEF, 2014; Reports WEF, 2015). However in 2013 they went further and singled out "scientific 
risks" which may seem surd but need attention, in particular: intervention into a human brain, efforts to control climate, rapid change of the condition of the Earth atmosphere, prolongation of live and expenses on old people connected with this, neglect of rules of human ethics as doping in sports. According to experts, who took part in preparation of the report, in the future these factors could trigger a global disaster.

Talking about technological solutions and scientific research quite a few modern researchers and scientists will lose the chance to voice concern and call for vigilance. First of all, this concerns biotechnologies where research and use has long become a separate subject of consideration (Report on Biosecurity... 2011). This related to the risks of maintaining by living organisms of their biological entity, their biological properties, systematically important connections and characteristics, prevention of large-scale loss of biological integrity.

Questions of biosafety and appearance of frequently unwilled or malevolent actions have forced to take a new look on the problem of dual use of sciences and technologies. The concept of "dual use" in relation to science, research and technologies has its own history and is not unique for life sciences. Dual use just literally means that a certain activity or a certain object can be used at least in two or more ways. This relates to the vast majority of things that we create. At the same time, the notion of "dual use" potentially meant completely opposite actions, which frequently were alternative, or caused unintended functions. For instance, a kitchen knife can be used for cutting food or as a screwdriver, but sometimes it is also a murder weapon. Whereby, the knife manufacturers did not even suppose its use for this purpose. Medical drugs are used for treating human diseases, but can be also used for committing a suicide when taken in large quantities. Being a kind of the air transport, planes are used to carry passengers for long distances, but in the certain situation on $11^{\text {th }}$ September 2001 they became a mass murder weapon in hands of terrorists. Another example is with the 3D printer, when in May of 2013 an American Cody Wilson developed and printed on a serial 3D printer a working pistol "The Liberator", which used standard $9 \mathrm{~mm}$ shells. After successful tests of the weapon, its blueprints were published for a free access in the Internet and more than 100 thousand people downloaded them just in two days! (Decree of the Government ... No. 447, 2001).

\section{RESEARCH RESULTS}

It happened historically so that the notion of "dual use technologies" or "dual-purpose technologies" are considered to be synonyms in Russia. They are mainly used in relation to their peaceful or military usage connected with different mass destruction weapons: nuclear, chemical and biological (GOST 31278-2004). The present inter-state standard of the CIS member-countries gives the following definition: «2.2.21.dual-use technology: The aggregate of scientific -technical knowledge, processes, materials, equipment and intellectual property objects which can be used during development, manufacture, use, modernization and disposal of military and civil use products" (Kovtun and Polonskaya, 2012). "Dualuse" technologies in Russian science and practice presuppose mainly peaceful or military targets (Michael, 2009).

Meanwhile, huge experience has been gained in the world in recent years concerning discussion and formation of both technological approaches and practical recommendations for understanding the necessity of controlling and regulating dual-use technologies, especially in life sciences (Michael, 2009).

Not least this was connected with publications in the sphere of biology about revolutionary achievements used in medicine and pharmaceuticals. At the same time there appeared apprehensions that results of those research as well as those in other spheres could be used for terrorism. For example, in September of 2011 a group of scientists from the University of Rotterdam in the Netherlands announced at a conference in Malta that they successfully created a highly virulent lethal pattern of the H5N1 virus of the bird flu which can be transmitted to mammals. The story was quickly caught up by popular science Mass media and already by December the deadly sensation was the focus of attention of the whole world. Nearly at the same time, the Nationals Science Advisory Board for Biosecurity (NSABB), a consultative body with the deliberative vote in the US government, recommended that the results of the research and detailed methods of production of the lethal virus should be published in the edited form to prevent its replication by separate persons or governments with evil purposes.

- In the discussion that followed it became clear that the Dutch scientists who carried out experiments with H5N1 absolutely did not know about potential biological biosecurity and ethical and legal questions which appeared in connection to their work.

- Another reason hampering reaching the consensus was that there were mechanisms on site for spreading results of the research on the basis "of necessity of familiarization with it".

- In the end of March 2012, the US government started debates, classifying the high risk of such scientific researches for food safety. Nearly at the same time, the NSABB changed its position having permitted the Dutch scientists to publish results of their research in the Science magazine.

There are several approaches to solution of this problem or even several problems. Thus, using the analysis of scientists' codes of conduct, which define limitations caused by potential dangers of dual use technologies and research, Michael J. Selgelid makes a conclusion about insufficiency of corporate regulation of these problems inside the scientific community and proposes that they should become a part of broader regulatory surveillance system (Dubov, 2014).

Another proposal made by a researcher Alex Dubov in related to transition from limitations to developing a policy of security, from confidentiality to openness, from segregation to strengthening the public voice. He connects it with the fact that rapid development of life sciences in the context of increased international concern about potential abuse caused the absence of concord in questions of responsibility, control and interaction. He stated that the advance of knowledge is in advance of efforts to develop moral and legal regulating principles of revealing and minimizing risks in the process of research. He focuses on questions of security and global cooperation in scientific research, underlying the importance of 
openness, favorable policy and cooperative management. He thinks this can be a certain guarantee for decreasing risks and letting important research go ahead (Van Rensselaer, 1971).

The main general result of the research is the need for ethical and legal regulation of the risks of dual-use science. The foundation for the development of the core of the new mode consists of the development of interdisciplinary and converging technologies on the basis of the cross-over use in different combinations of achievements in nanotechnologies, advanced bio- and info-technologies as well as achievement in other spheres of science and technique not related to that system-forming within the new mode. These interdisciplinary or converging technologies, which are the drive of the new technological headway, will provide both appearance of principally new kinds of goods and services and the production of traditional goods and services, having properties and parameters, which were unachievable within the previous modes.

As a consequence, the uncertainty of the global development is growing, the speed of changes of a number of key world economic tendencies increases and new threats appear. The analysis of scenarios of the future requires original approaches, scenarios of the "advanced" development, ethical "internal optics" of critical technologies in a situation maximum close to the "field conditions", involvement of specialists of the most diverse profiles.

\section{CONCLUSIONS AND DISCUSSION}

This emphasized the necessity of speeding-up the examination, forecast and development of means which should promote sustainable development, provide security and quality of life of population, protect environment and improve efficient use of natural recourses. It is quite clear, that with the development of the modern architecture of science and large-scale introduction of post-biological technologies there will be increased necessity in public control mechanisms. The analysis, evaluation and choice of tools for decreasing these risks are becoming imperative and this means that the importance of such tools of ethic regulation as bioethics will increase.

The phenomenon of bioethics owes it appearance to wide introduction of modern biomedical technologies into medical practice under the conditions of developing democratic processes in the second half of the XX century (Sass, 2007; Nezhmetdinova, 2013). Currently, on the one hand, bioethics is a recognized scientific sphere of interdisciplinary knowledge, the subject of which is the assessment and choice of a moral criterion of the attitude to the alive. On the other hand, it is the social practice of ethic regulating clinical research and medical activity approved by the world community. It is absolutely clear that with the development of the modern architecture of science on the basis of the convergence of NBIC technologies, the necessity in public control mechanisms will grow and this means that the importance of bioethics will increase. Widening the field of discourse of bioethics, the possible extrapolation of its assessment-regulation role and experience of its use as a tool of humanitarian expertise in the sphere of ecology, introduction of biotechnologies into agriculture, professional sport and so on becomes more and more in demand.

Bioethics is defines as an interdisciplinary field of knowledge, the subject of which is the assessment and choice of a moral criterion of the attitude to the alive. It has been formed as:

- Humanitarian expertise

- Interdisciplinary dialogue platform

- Social technologies of regulation of new technologies risks, development and changes of "material germinating power"

- Constructive communication of the power, business, scientists and society

- Support and spreading of scientific research and social projects aimed at preservation of health and wellbeing of man and nature

- "internal optics" of moral attitude to the alive and dogmatic imperative of science and technologies

- The condition for development of the public society and governance of law.

The existing successful scientific-research and practical groundwork in bioethics in medicine proves the potential possibility of broadening the use of concept and practice of bioethics as a humanitarian expertise for the whole spectrum of analysis of possibilities and risks of development and use of results of modern converging technologies.

\section{REFERENCES}

1. Beck U. 2000. Risk society. On a way to another modern. Moscow.

2. Decree of the Government of the Russian Federation of 7 June 2001 No. 447 "Regulation on control of foreign economic activity concerning the goods and dual-use technologies that can be used to create weapons and military equipment" Available at http://base.garant.ru/12123212/\#ixzz3pJm529E4] (accessed on 12/05/2017) [In Russian)

3. Dubov. A. 2014. The concept of governance in dual-use research. Medicine, Health Care and Philosophy, Vol. 17, Iss. 3, pp. 447-457.

4. Frischknecht, F. 2014. Biological Warfare: From History to Current Affairs. 2014. Available at http://onlinelibrary.wiley.com/doi/10.1002/9780470015902.a0003290.pub3/full (Accessed on 12/05/2017).

5. Global Technology Revolution 2020. In-Depth Analyses: bio/nano/materials/information trends, drivers, barriers, and social implications. 2006. Technical Report. Richard Silberglitt et al. RAND. National Security Research Division. Santa Monica, CA. Available at http://www.rand.org/pubs/ technical_reports/2006/RAND_TR303.pdf (Accessed on 12/05/2017).

6. Interstate standard. GOST 31278-2004: Cooperation of States-participants of the Commonwealth of Independent States militaryeconomic. (Electronic resource) Terms and definitions. Available at http://standartgost.ru/g/\%D0\%93\%D0\%9E\%D0\%A1\%D0\%A2_31278-2004 (Accessed on 12/05/2017). 
7. Johnston, R. 2011. Analysis of future-oriented technology: the problem of Cassandra. Foresight, No. 2(5), pp. 58-64.

8. Kovalchuk, M.V. 2011. Convergence of Sciences and technologies - breakthrough to the future. Nanotechnologies in Russia, Vol. 6, pp. 13-24. https://doi.org/10.1134/S1995078011010149

9. Kovtun, A.L., Polonskaya, D. L. 2012. Analysis of the significance of technology in modern consideration of problems of biological safety. Molecular medicine, No. 5, pp. 1-8.

10. Magner, L.N. 2002. A history of the life sciences (Rev. and expanded 3rd ed.). New York: M. Dekker. 2002.

11. Michael, J. 2009. Selgelid Dual-Use Research Codes of Conduct. Lessons from the Life Sciences NanoEthics, Vol. 3, Iss. 3, pp. 175-183.

12. Nezhmetdinova, F.T. 2010. Bioethical expertise as a basis for biosafety. Hazards - detection and management. Book of abstracts. 6-th Dresden Symposium, pp. 27-34. September 20-24, 2010 Dresden, Germany, SARAD, Dresden University of Technology.

13. Nezhmetdinova, F.T. 2013.Global challenges and globalization of bioethics. Croatian Medical Journal, Vol. 54(1), pp. 83-85. https://doi.org/10.3325/cmj.2013.54.83

14. Pride, V., Medvedev, D. 2008. The phenomenon of NBIC-convergence: Reality and expectations. Philosophy of Science, Vol. 1, pp. 97-117.

15. Roco M., Bainbridge W. 2004. Converging Technologies for Improving Human Performance: Nanotechnology, Biotechnology, Information Technology and Cognitive Science, Arlington.

16. Reports OECD "Looking -2060. Long term growth prospects world". Available at http://espas.eu/orbis/document/looking-2060long-term-growth-prospects-world (Accessed on 12/05/2017).

17. Report on Biosecurity and Dual Use Research. Dutch Research Council. 2011. Available at http://www.bbc.co.uk/russian/society/2013/05/130509_us_printed_gun_downloads.shtml (Accessed on 12/05/2017).

18. Reports WEF “Global risks 2013” Available at http://reports.weforum.org/global-risks-2013/ (Accessed on 12/05/2017).

19. Reports WEF “Global risks 2014” Available at http://reports.weforum.org/global-risks-2014/ (Accessed on 12/05/2017).

20. Reports WEF “Global risks 2015 Available at http://reports.weforum.org/global-risks-2015 (Accessed on 12/05/2017).

21. Van Rensselaer, P. 1971. Bioethics: Bridge to the future. Englewood Cliffs, N/J.: Prentice-Hall.

22. Sass, H.M. 2007. Fritz Jahr's 1927 concept of bioethics. Kennedy Institute of Ethics Journal, Vol. 17(4), pp. 279-295. https://doi.org/10.1353/ken.2008.0006 